\title{
JANSENISMO Y RIGORISMO EN LA NUEVA ESPAÑA: UNA PROPUESTA DE RENOVACIÓN HISTORIOGRÁFICA (1660-1700)
}

\author{
Trilce Laske* \\ Universidad Nacional Autónoma de México
}

\section{INTRODUCCIÓN}

T a mañana del 12 de junio de 1676, el prepósito de la Casa LProfesa capitalina, Francisco Carboneli, fue denunciado al Santo Oficio por haber promovido, ante sus subordinados, la limitación de la comunión de los fieles seglares, solteros o casados, a un máximo de una vez por semana. ${ }^{1}$ Frente al alcance de esa acusación, el inquisidor Martín de Soto Guzmán decidió el mismo día abrir una investigación y transmitió inmediatamente el expediente a su fiscal. ${ }^{2}$ Apenas 14 años más tarde, en 1690, la

Fecha de recepción: 3 de diciembre de 2019

Fecha de aceptación: 30 de marzo de 2020

* Programa de becas posdoctorales en la unam. Becaria del Instituto de Investigaciones Históricas, asesorada por el doctor Iván Escamilla.

1 "decía que los de su instituto exsortasen a sus penitentes de dichos estados [seglares ya solteros o casados] a que no frequentasen si de ocho a ocho días el Santissimo Sacramento de la Eucharistía", AGN, Inquisición, vol. 627, exp. 4, f. 166 r.

2 "Luego incontinenti [...] el S[en]or Inqu[isi]dor mandó que se saque esta denunciación, con los papeles exhibidos se forme proceso en forma y se entregue al S[en]or Inqui[si]dor fiscal”, AGN, Inquisición, vol. 627, exp. 4, f. $168 \mathrm{r}$. 
situación era no obstante distinta. Los defensores de la moderación respecto a la frecuencia de comunión de los fieles se encontraban ya suficientemente bien establecidos en la capital virreinal como para que un correligionario de Carboneli, de la dimensión de Antonio de Núñez, tratara de contradecirlos dialécticamente en una obra de difusión corriente, su Comulgador penitente. ${ }^{3}$ En paralelo, los calificadores inquisitoriales se dedicaban a recomendar la prudencia en la administración del sacramento, mientras que la acusación de su exceso se había convertido en un arma política para deshacerse de adversarios inoportunos. ${ }^{4}$ ¿Cómo explicar tal inversión respecto a la frecuencia de la comunión y la rapidez de su difusión? Como respuesta, este artículo busca demostrar que este cambio resultó del rápido desarrollo (40 años) en la Nueva España de una cultura teológica severa, la cual modificó profundamente la moral católica y se expandió simultáneamente en otros espacios de la cristiandad.

En efecto, diferentes trabajos han puesto de relieve desde hace tiempo el surgimiento y la expansión, a partir de la década de 1650, de un rigorismo inédito en Holanda, Francia, Italia e incluso Inglaterra. ${ }^{5}$ Generado y difundido por sectores múltiples, tanto eclesiásticos como universitarios y seglares, este fenómeno habría constituido inicialmente una reacción severa a la cultura

3 "Y porque algún crítico, de los que ni aun cada ocho días toleran, o aprueban la Comunión de personas seglares, no nos rebuelba de insoluble argumento nuestra prueba principal...”, NúÑEz, Comulgador, y explicación, f. 3r. Véase también: "los afrontados extremos, que acerca de la frecuente comunión, han chocado este siglo. Facilitándola unos, sin límite de personas, ni diferencia de grados, hasta la quotidiana a todos: quando otros parece, la dificultan, hasta cada año", NúñEz, Comulgador, y explicación, f. 1r.

${ }^{4}$ El 12 de junio de 1695, los calificadores franciscanos José Sánchez y Antonio de Escoto escribieron: "se requiere para llegar frequente o quotidianamente a la sagrada comunión una preparacion grande”, AGN, Inquisición, vol. 534, f. 252r. Para la instrumentalización del exceso de la comunión como arma, véase, por ejemplo, AGN, Inquisición, vol. 688, exp. 3, ff. 347-418.

${ }_{5}^{5}$ Michel, Jansénisme et Paris; Quantin, Le rigorisme chrétien; Baustert, Le jansénisme et l'Europe. 
teológica y pastoral, pensada en Trento, para contribuir luego durante las décadas siguientes a una mutación importante de las nociones de consciencia y verdad. No obstante, no habría afectado las esferas hispánicas y germánicas, para las cuales la emergencia de esta nueva severidad es pospuesta por la historiografía en una fecha más tardía, el siglo xviII. En el caso del Imperio hispánico, ésta remite además principalmente a una de las vertientes más visibles del rigorismo, el jansenismo, promovido con base en intereses políticos por los sectores específicos del Estado regio y sus servidores. ${ }^{6}$ De hecho, la expulsión de los jesuitas por parte de la corona se basó en efecto en acusaciones de laxismo, ampliamente difundido por los jansenistas. Sin embargo, en el caso de la Nueva España, una reacción severa, más amplia que el jansenismo, es observable bastante tiempo antes, desde la mitad del siglo XVII, en consonancia con la cronología de su expansión en otros espacios de la cristiandad europea. En vez de ser fomentada desde el aparato de Estado por las instancias reales, se expresó además por medio de actores diversos, tanto clericales como laicos.

El objetivo de este artículo es, por lo tanto, triple. Primero, busca proponer una periodización renovada del desarrollo del rigorismo en el virreinato americano. Temprana, la reacción severa en la Nueva España conoció un periodo de progresión inicial (1660-1681), seguido por una tentativa de contención por parte de algunos adversarios entre los cuales destacó el arzobispo Aguiar y Seijas (1682-1698), para finalmente terminar con la victoria de un rigorismo moderado (1698-1700). Segundo, más allá de las similitudes con otros espacios católicos, este texto se dedica también a subrayar las singularidades del rigorismo novohispano que, a diferencia del

${ }^{6}$ MiguéLez, Jansenismo y regalismo en España; Tomsich, El jansenismo en España; Callahan, Iglesia, poder y sociedad en España. Para el caso específico de la Nueva España véase BRAding, "El jansenismo español”. 
de Holanda o Francia, desatendió los debates de teología dogmática para concentrar sus preocupaciones en la casuística y los sacramentos. Tercero, se trata aquí de interrogarse de manera general sobre la emergencia y expansión en la Nueva España de una nueva cultura teológica de contornos transatlánticos.

\section{LA APARICIÓN DEL RIGORISMO EN LA NUEVA ESPAÑA: CONFLUENCIAS EXITOSAS ENTRE PREOCUPACIONES LOCALES Y SUPRARREGIONALES (1660-1682)}

El rigorismo se ha reducido a menudo a una de sus manifestaciones, el jansenismo, probablemente con base en la gran visibilidad que le dio a éste su dimensión polémica y combativa. Fue no obstante un fenómeno más amplio y complejo que, durante la segunda mitad del siglo XVII, socavó progresivamente las bases de la cultura teológica vigente. Heredera de los reformadores tridentinos, esta cultura se caracterizaba en aquel tiempo por un manejo flexible de las inquietudes de la feligresía y por la preocupación de mitigar el peso de las obligaciones que cargaba. ${ }^{7}$ A partir de la década de 1640, este planteamiento empezó a ser entendido como indulgencia o incluso relajación por varios sectores que penetraron con grados diversos en tres de sus terrenos mayores: la dogmática, la casuística y la pastoral. ${ }^{8}$ Primero, la teología dogmática constituyó un espacio de afirmación de una nueva severidad en torno a la relectura, entre otros, de Agustín por Cornelio Jansenio. En continuidad con los debates sobre la gracia, diferentes sectores, particularmente en Holanda, endurecieron las condiciones de acceso a la salvación tanto a los viejos cristianos como a los neófitos recién convertidos, mediante la reactivación del concepto de predestinación o de la reprobación

\footnotetext{
7 Delumeau, L'aveu et le pardon, pp. 141-150. Para el uso de cultura, Gay, "Laxisme et rigorisme".

¿ Para un análisis detallado, véase Quantin, "Le rigorisme".
} 
de la ignorancia invencible (la ignorancia involuntaria de la ley perdona el pecado).

Segundo, algunos sectores rigoristas arremetieron contra la casuística y su vertiente principal: el probabilismo. Desde finales del siglo xvi, los casos morales se resolvían principalmente con el sistema de las opiniones probables. ${ }^{9}$ En una situación de duda sobre la interpretación de la ley, se trataba de seguir el parecer emitido más o menos explícitamente por una autoridad antigua o moderna, sea mayoritaria o incluso minoritaria entre los teólogos. ${ }^{10}$ Originado por la consciencia de la tensión entre el carácter único de las situaciones y la dimensión universal de la ley, este sistema favorecía la libertad individual dejando la posibilidad de una elección. Sin embargo, en la primera mitad del siglo xviI, el probabilismo fue modificado por una multitud de autores, quienes, por distinción personal, estrategia política o sincera convicción, dilataron su alcance. Ayudados por un mercado editorial dinámico, así como por el mecenazgo del papa Urbano VIII (1623-1644), diferentes probabilistas incrementaron considerablemente el radio de aplicación de las opiniones probables, como por ejemplo respecto al homicidio. ${ }^{11}$ Interdicción estricta del decálogo, el homicidio se llegó a legitimar en el caso de afrenta al honor (capital social) o asalto al patrimonio (capital económico) sobre

9 Para una historia del probabilismo y de sus versiones sucesivas, véase Schuessler, The Debate on Probable Opinions.

10 Por ejemplo, la definición de Millar: "El probabilismo es [...] aquella doctrina teológico-moral que señala que en caso de duda respecto de si es lícito o no emprender una acción determinada, se puede seguir la opinión probable, aun existiendo otra más probable". MiLlar, "El obispo Alday y el probabilismo", p. 189. Sobre el desarrollo del probabilismo: HurTubise, La casuistique dans tous ses états; MAYER, Rutas de incertidumbre.

${ }_{11}$ Urbano VIII y sus familiares llevaron una política de mecenazgo muy favorable al probabilismo. Por ejemplo, protegieron al teatino Antonino Diana, figura emblemática del probabilismo. Schuessler, The Debate on Probable Opinions, p. 127. 
la base argumentativa de la probabilidad de las opiniones. ${ }^{12}$ Esta extensión del campo de aplicación del probabilismo fue entendida obviamente como un exceso por parte de un sector católico y provocó la aparición de un antiprobabilismo, más o menos virulento, que conoció dos versiones: el probabiliorismo y el tuciorismo. Menos radical, el probabiliorismo conservaba el interés de las opiniones probables para la casuística, pero imponía optar por la opinión más probable, más segura (opción dominica). Más exigente, el tuciorismo promovía la observancia estricta de la ley, descartando las opiniones (opción jansenista).

Tercero, la pastoral sacramentaria fue también cuestionada en torno a dos sacramentos en particular: la penitencia y la comunión. A nivel de la primera, la estrategia clerical había sido hasta entonces de tolerancia. Por una parte, el clero se había conformado con la atrición simple (arrepentimiento por miedo al infierno) en vez de la contrición (arrepentimiento por amor a Dios). Por otra, la absolución sistemática de los pecadores reincidentes había sido aceptada como un mal menor frente al riesgo de verlos alejarse de la Iglesia. A nivel de la comunión, se había pensado en su administración con base en criterios de accesibilidad, en una voluntad de acercamiento de los feligreses hacia Dios. Ahora bien, para los sectores rigoristas, esta política sacramentaria había llevado en ambos casos a la devaluación de los sacramentos referidos. ${ }^{13}$ Promovieron pues un endurecimiento de sus condiciones de administración por medio de tres modalidades nuevas: la retención de la absolución para los

12 Por ejemplo, una opinión probable sobre el homicidio para los clérigos: "Es lícito a qualquier religioso, o clérigo matar al calumniador que amenaza publicar enormes delictos de ellos, u de su Religión, quando no ay otro modo para defenderse". Velasco, Breviloquio moral, f. Vr. La opinión fue condenada luego en 1665 por el papa Alejandro VII.

${ }^{13}$ Esa fue por ejemplo una posición defendida de manera temprana por los jansenistas, con la obra de Antoine Arnauld, De la fréquente communion, publicada en 1643. 
reincidentes, la exigencia como mínimo de una atrición sobrenatural y la disminución de la frecuencia de la comunión.

Aceptados por grados distintos según los actores, estos tres ejes de severidad no coincidían necesariamente. De hecho, la reacción rigorista novohispana fue desigual. No sólo ignoró inicialmente la vertiente de teología dogmática, sino que también su primer frente fue el probabilismo, antes incluso que la pastoral sacramentaria. Sobre todo, su desarrollo fue discontinuo, tributario de factores tanto internos como externos al virreinato. En este sentido, antes de chocar con una resistencia institucional a partir de 1682, el rigorismo novohispano conoció dos fases iniciales. De la década de 1660 a 1679, se trató de un rigorismo de orden antiprobabilista, en gran medida impulsado por la orden de Santo Domingo. En cambio, a partir de 1680 y de la implicación de la curia romana, los actores se multiplicaron y la cuestión pastoral emergió a su vez como problemática severa.

Como para otros espacios católicos, los primeros promotores de una nueva severidad en el virreinato fueron los dominicos. Ya desde la década de 1640, algunos teóricos de la orden habían empezado a impugnar públicamente el probabilismo y sus obras se habían difundido dentro de la institución regular. ${ }^{14}$ Luego, en 1656, el Capítulo General reunido en Roma impuso, por decreto, la obligación para sus miembros de suscribirse al probabiliorismo..$^{15}$ Esta institucionalización temprana de un antiprobabilismo como doctrina oficial para la escuela de teología moral dominica respondía entonces para las instancias centrales tanto a consideraciones morales como a dinámicas políticas. Además de la consciencia de los excesos de la casuística probabilista, se trataba a la vez de ganarse los favores

14 Concina, Historia del probabilismo, pp. 223-224.

15 Concina, Historia del probabilismo, p. 19. Una vertiente con mucha repercusión de esta obligación fue la enseñanza. 
del papa reformador Alejandro VII y de una estrategia de diferenciación respecto a la Compañía de Jesús, que contaba con numerosos teóricos probabilistas entre sus miembros. En efecto, a comienzos del siglo, los dominicos se habían enfrentado duramente con los jesuitas en torno a la gracia divina en la polémica de auxiliis. Si bien para los primeros la salvación dependía de la gracia divina (gracia eficaz), para los segundos, la libertad humana también jugaba un papel importante (gracia suficiente). Muy exacerbados, los debates sobre el tema habían sido prohibidos en 1607 por un decreto papal. Sin embargo, dejaron heridas duraderas entre ambos bandos y una animadversión fuerte. ${ }^{16}$ En ese contexto, el rechazo al probabilismo y la adhesión a la alternativa probabiliorista de parte de los altos círculos dominicos constituyó también una señal de diferencia respecto a sus adversarios jesuitas. De hecho, si bien no fue desprovista de oportunismo, esta adhesión de las instancias superiores de la orden constituyó un factor decisivo para la difusión del antiprobabilismo dentro de la institución. En la provincia de Castilla condujo a la uniformidad doctrinaria mediante, por ejemplo, la promoción de miembros fuertemente antiprobabilistas. ${ }^{17}$

En la provincia de Santiago de México, las primeras manifestaciones de un antiprobabilismo militante empezaron a darse al comienzo de la década de $1670 .{ }^{18}$ En 1671, el dominico y

${ }_{16}$ Gallegos Rocafull señala la gran cantidad de manuscritos latinos de jesuitas y dominicos novohispanos conservados sobre la controversia de auxiliis en la BNM. Gallegos Rocafull, El pensamiento mexicano, pp. 244 y 247. Todavía en 1690, el dominico Juan Bautista Méndez pedía al Santo Oficio de México la prohibición de unas conclusiones sobre el tema que se iban a defender en el Colegio de San Pedro y San Pablo de los jesuitas. AGN, Inquisición, vol. 679, exp. 5.0

17 En 1662, la provincia de Castilla eligió como provincial a un notorio teórico del probabiliorismo, Juan Martínez de Prado.

${ }_{18}$ No descartamos en absoluto que haya habido otras manifestaciones antes. De hecho, en 1661, un dominico de la provincia filipina, Francisco Pérez, 
novohispano Agustín Dorantes, docente del colegio Portacoeli, aconsejó al Santo Oficio que recogiera y expurgara la edición de 1668 del Tesoro de la sciencia moral del benedictino Anselmo Gómez. ${ }^{19}$ Aunque era un probabilista moderado, ${ }^{20}$ el benedictino defendía en efecto la existencia de opiniones indulgentes sobre cuestiones como la solicitación de los curas o el ayuno. Para los inquisidores, Dorantes fundó su solicitud con base en una argumentación antiprobabilista clásica, la cual, si bien no promovía el probabiliorismo ni el tuciorismo, denunciaba el exceso de algunas opiniones probables frente a las exigencias de la ley. El dominico llegó incluso a deplorar: "Lo q[ue] yo me admiro, y no acabo de entender, como los Señores Inquisidores, alias tan escrupulosos en otras materias graves, en esta no tildan las opiniones err[one]as". ${ }^{21}$

Durante los años siguientes, una dinámica conflictiva hizo evolucionar luego este primer antiprobabilismo novohispano, el cual cambió entonces de amplitud. Si bien con Dorantes había sido reservado, el antiprobabilismo salió del espacio cerrado de los claustros dominicos y de las oficinas inquisitoriales hacia el espacio público. Durante el transcurso del año de 1676, el dominico Francisco Sánchez, vicario de San Jacinto en la ciudad de México, hizo publicar un pequeño tratado en las Filipinas. ${ }^{22}$

denunciaba ya una obra de otro probabilista notorio, Juan Caramuel. AGN, Inquisición, vol. 759, exp. sin núm., f. 470r-480r.

19 AGN, Inquisición, vol. 515, exp. sin núm., f. 572r.-576v.

20 "Digo, pues, que absolutamente es lícito [seguir opinión probable, dexando la cierta y segura] en todas materias, salvo en lo que toca a las partes intrínsecas, y esenciales de los Sacramentos”. Gómez, Tesoro de la sciencia moral, p. 117. 21 También: "relaxaciones de las consciencias, con novedad intolerable". Ambas citas en AGN, Inquisición, vol. 515, exp. sin núm., f. 576r.

22 Según el propio Sánchez: “yo lo escribí en esta Ciudad de México, año de 1674 y se imprimió primera vez en las Islas Philipinas año de 1676”. SánCHEz, Thesoro regvlar, p. 2. Desgraciadamente, no hemos podido localizar la edición mencionada, ni siquiera en catálogos. Sin embargo, tenemos un acceso parcial al texto, pues Sánchez lo volvió a publicar con algunas modificaciones en 1680. Véase SÁNCHEZ, Examen de las indulgencias, tratado I. 
Se trataba de un repertorio breve de las indulgencias válidas para los regulares y cofradías. Muchas habían sido revocadas en 1606 por los papas Pablo V y Alejandro VII, quien acababa, en marzo de 1666, de confirmar su nulidad. Sánchez pretendía pues simplemente actualizar la lista de las indulgencias y, en el proceso, descartar las que eran nulas y se seguían empleando. ${ }^{23}$ Para difundirlo en México, fray Francisco mandó traer varios ejemplares desde Manila, los cuales se distribuyeron rápidamente entre los letrados novohispanos. ${ }^{24}$

De manera inesperada, la obra provocó inmediatamente una polémica en México, la cual colocó en el centro de los debates intelectuales la cuestión probabilista y radicalizó la posición dominica. Según Sánchez, "levantó contra él [su tratado] tanta borrasca de contradicciones, q[ue] causa admiración". ${ }^{25}$ Desencadenó la difusión en la esfera urbana de obras, cuadernos e incluso folletos clandestinos, redactados por jesuitas y franciscanos cuyo objetivo era preservar la validez de algunas indulgencias que Sánchez afirmaba nulas. ${ }^{26}$ Para ello, se apoyaron

${ }^{23}$ Sánchez volvió a explicitar su propósito inicial en 1680: "dar algunos avisos para el conocimiento de las Indulgencias ciertas, y seguras de las Religiones y Cofradías; y para que se sepa con claridad quales están revocadas, y quales son evidentes", SÁNCHEZ, Examen de las indulgencias [f. 9r.-v.].

${ }^{24}$ Beristáin y Retana discrepan sobre la procedencia de Sánchez. Para Beristáin, el dominico fue originario de México y profesó en la misma ciudad en 1634. Para Retana, en cambio, nació en Toledo y profesó en Valladolid en 1644. Sea como fuere, para sus dos comentaristas madrileños de 1680, Sánchez estaba claramente asociado a América. Véase: "es de los mayores [este libro], que han venido de las Indias, no en comparación de los temporales [...], sino de muchos eruditos libros, que los grandes ingenios, y doctos, que tienen aquellos Reynos", SÁnchez, Examen de las indulgencias [f. 3r.]; "venir del Oriente donde se fixan las Indias", SÁnchez, Examen de las indulgencias [f. 4v.].

25 SÁnchez, Examen de las indulgencias, p. 90. En 1680, Sánchez hizo publicar en Madrid una obra en la que resumió desde su perspectiva la polémica. Volvió luego a tratar el tema en su obra poblana de 1691.

${ }^{26}$ Sobre la participación de jesuitas y franciscanos: SÁNCHEZ, Examen de las indulgencias, pp. 131-132, 287. También, en 1681, el provincial jesuita 
de manera clásica en la doctrina de las opiniones probables. Puesto que la confirmación de la revocación por Alejandro VII, en marzo de 1666, no se había oficializado en las Indias, era probable que ésta no obligara a nada en la Nueva España. En consecuencia, las indulgencias invalidadas por Sánchez seguían viables. Según un adversario:

[...] en las Provincias donde la tal proposición [de Alejandro VII], que trae V.P. (como el Aquiles de su sentir) no estuviere publicada, no causará el horror, que quiere que cause, como si estuviera intimada, y publicada en toda solemnidad; sino que se quedará en la probabilidad de que allí no obliga, según el parecer de tantos hombres doctos, e insignes. ${ }^{27}$

El registro argumentativo utilizado, de orden probabilista, empujó a Sánchez a replegarse en un antiprobabilismo radical: el tuciorismo en materia de indulgencias. En su respuesta publicada en 1680, se dedicó detenidamente a extraer del campo de aplicación del probabilismo las indulgencias. Éstas debían ser sometidas únicamente a un régimen de lo verdadero o lo falso,

consultó a la sede romana de la Compañía sobre el tema, pues el 14 de febrero de 1682, el vicario le escribió al respecto: "Digo a la pregunta q VR añade: que aunq es verdad q el Papa Paulo V en su bulla expedida al 23 de mayo de 1606 revocó todas las indulgencias concedidas hasta aquel día a todas las religiones y personas regulares: pero en la misma bulla concedió otras indulgencias peculiares a todos los religiosos comunes [...]. Conq en virtud de la Proposición 37 condenada por Alex VII no puede con razón decir ese libro $\mathrm{q}$ dize VR que ha salido q no ay indulgencia q tenga valor". Carta del vicario a Gerónimo de Figueroa, ARSI, México 3, 158r.

27 Sánchez lo citó directamente: SÁNCHEZ, Examen de las indulgencias, p. 148. También "De donde no es bien que V.P. quite en la Iglesia probabilidades, donde ella no las quita". SÁnchez, Examen de las indulgencias, p. 150. Más allá del probabilismo, el argumento de la distancia fue aprovechado a menudo por los grupos eclesiales según sus intereses, como en la polémica del año santo de 1700 o del Patronato Guadalupano en 1737. Escamilla, "Reformar la reforma"; LASKE, Trajectoires, postures et modes d'action. 
decidido por la Santa Sede, y de ninguna manera depender de las opiniones:

Ordinariamente se dize, que quien obra con opinión probable, no peca, que es decir, que obra evidentemente bien [...]. Esto dizen los Autores comúnmente; pero añaden, que esta doctrina no corre en algunas materias, y son aquellas cuyo valor, o ser de la cosa no se mide por discursos prudenziales, ni por juizios, sino por realidades; como sucede en lo que toca en materias, y formas del sacramento; y lo mesmo dizen en materia de Indulgencia; cuya existencia, y valor, ni se aumenta, ni se quita por dictámenes de Doctores. ${ }^{28}$

Siguiendo un modelo polémico clásico, diferentes ofensivas salieron además del marco dialéctico y apuntaron no sólo contra la figura de Sánchez sino también contra su orden. ${ }^{29}$ En una lógica corporativa, estos ataques llevaron evidentemente a aumentar la implicación en el conflicto de los dominicos, quienes se federaron detrás del tuciorismo argüido por Sánchez (dinámica identitaria). Durante los años siguientes, éste fue elevado al Provincialato en señal de reconocimiento tanto de su persona como de su doctrina. ${ }^{30}$ Sobre todo, los dominicos de Nueva España dedicaron desde entonces una atención

28 Sánchez, Examen de las indulgencias, p. 7. También: "aunque todos los Doctores la prueben con realçadisimos discursos, y sea opinión probable, o la más probable, y común, ni será, ni se ganará [si no es cierta la indulgencia]", SÁNCHEZ, 1680, p. 8. Véase también SÁnchez, Examen de las indulgencias, pp. 24 y 27.

29 “[...] por injuriar también a dicho Author, y que también clandestinamente empezaron a correr, pasaron con venenosas razones, agudas saetas contra inocentes, y rectos de coraçon, que debieran ser dulzuras, a querer empañar lo más docto, lo más santo de mi sacratissimo Orden de Predicadores”. SánchEz, Thesoro regular [f. 4r].

30 Según la portada de su Rosario de la virgen María, en 1684 era provincial de la provincia filipina. Sánchez, Rosario de la Virgen María. La elección de Sánchez se asemeja a la ya mencionada de su par castellano, Juan Martínez del Prado, en 1662. 
particular a las indulgencias y a su apartamiento del campo de aplicación del probabilismo. En 1677, el provincial dominico Antonio Leal de Araujo fue en persona al Santo Oficio para denunciar un libro de indulgencias para franciscanos. ${ }^{31}$ Luego, el 23 de diciembre de 1682, Agustín Dorantes, exrector ya del colegio Portacoeli, afirmó a los inquisidores que se disponía a publicar "las indulgencias ciertas y legítimas q[ue] sin duda alguna goza [la] Archicofradía del S[antissi]mo Sacram[ent]o". 32 Cuatro años más tarde, el 7 de febrero de 1686, otro dominico, el novohispano Nicolás de Merlo, denunció a su vez al Tribunal de la Cruzada un opúsculo sobre las indulgencias de la Cofradía de a Sangre de Cristo, autorizado por Alonso Alberto de Velasco. ${ }^{33}$ Para Merlo, "todo él no es más que un acervo de confusión, y contradicciones con los legítimos Sumarios". ${ }^{34} \mathrm{Su}$ denuncia, que hizo pública, le atrajo críticas. ${ }^{35}$ Para defender su posición, redactó tres meses después, en mayo de 1686, un largo texto en el que reivindicaba a su vez un tuciorismo estricto en materia de indulgencias como la incapacidad del probabilismo para evaluarlas:

No se halla potencia en el mundo que las haga verdaderas [las indulgencias], aunque se junten quantos Letrados, Canonistas, y Teólogos ay en el universo; y que cada uno vaya dando, v.gr. un ciento de pareceres en aprobación de ellas: porque si el Papa, o no

\footnotetext{
${ }^{31}$ AGN, Inquisición, vol. 633, exp. 10.

${ }^{32}$ AGN, Inquisición, vol. 643, exp. 2, f. 276v.

33 AGN, Inquisición, vol. 498, exp. sin número, f. 203r.-223r.

${ }^{34}$ AGN, Inquisición, vol. 498, exp. sin número, f. 211r.

35 " [...] he experimentado lo contrario, por aver visto los aplausos que se han dado al aprobador del Sumario, y los vituperios que ha recibido el denunciador". AGN, Inquisición, vol. 498, exp. sin núm., f. 210v.; "con lo dicho en estos discursos tengo entendido que se podrá responder a los quatro pliegos que algunos seglares han divulgado, que escribió contra mí el Aprobador".
} 
las ha concedido, o las ha revocado, no ay potencia (como dicho es) que pueda darlas por concedidas, o no revocadas. ${ }^{36}$

Este antiprobabilismo dominico novohispano se reactivó luego en 1691. Por un lado, Merlo hizo imprimir su pequeño tratado, el cual sus adversarios acusaron de haber "repartido dentro y fuera de ella [la ciudad de México], más de seiscientos [ejemplares]”. ${ }^{37}$ Por el otro, Francisco Sánchez volvió también al espacio público con una nueva obra sobre el tema. Con un tono muy polémico, el dominico reafirmaba su antiprobabilismo en materia de indulgencia y la supremacía de la ley: "aunque aya mil opiniones acerca de su existencia, no valdrá nada [la indulgencia]”. ${ }^{38}$

Para finales de la década de 1670, el conflicto sobre las indulgencias había planteado en el espacio público novohispano las problemáticas del debate en torno al probabilismo. Las líneas de divergencia entre los distintos adversarios eran en cambio todavía un poco borrosas. Si por un lado jesuitas y franciscanos calzados se suscribían a las opiniones probables, los dominicos empezaban a beneficiarse de aliados y apoyos fuera de la orden, en particular con los franciscanos descalzos. En 1680, un factor externo vino a acelerar esta adhesión: la publicación oficial en el virreinato de los nuevos decretos de Inocencio XI. Elegido el 21 de septiembre de 1676, el pontífice era un hombre convencido de la necesidad de un endurecimiento de las leyes de la Iglesia. Si bien los dominicos concentraban sus esfuerzos reformadores en la casuística, el nuevo papa tocó en cambio todas las vertientes de la reacción severa: dogmática, casuística y sacramentaria. El 12 de febrero de 1679, Inocencio XI firmó

\footnotetext{
36 AGN, Inquisición, vol. 498, exp. sin núm., f. 212v. Para la fecha de redacción del tratado: AGN, Inquisición, vol. 498, exp. sin núm., f. 223r.

37 AGN, Inquisición, vol. 498, exp. sin núm., f. 224v. Al parecer, el texto se imprimió en Puebla: "notorio escándalo en esta ciudad, y en la de los Ángeles, donde se presume se imprimió este papel”.

38 SÁnchez, Rosario de la Virgen María, p. 18.
} 
un primer decreto sobre la comunión para rechazar su administración frecuente a los seglares. Tres meses después, el 2 de mayo de 1679, firmó un segundo decreto que, por medio de la condena de unas 65 proposiciones, promovía el contricionismo y la retención de la absolución para los reincidentes. ${ }^{39}$ También prohibía la aplicación del probabilismo para el valor de los sacramentos, en favor del probabiliorismo. ${ }^{40}$ Ambos decretos eran fuertes $y$, en todo el espacio católico, contribuyeron a reconfigurar el equilibrio de las fuerzas. En la Nueva España, constituyeron un segundo acelerador decisivo para el auge de la moral severa después del precedente dominico. En su vertiente pastoral, los decretos hicieron emerger la cuestión sacramentaria. En su vertiente antiprobabilista, abrieron una nueva fase en la progresión del rigorismo en el virreinato al legitimar a sus partidarios, los cuales se multiplicaron.

En la capital, la publicación oficial de los decretos de Inocencio XI fue doble. Se promulgaron públicamente el miércoles 27 de marzo y el domingo 7 de abril de 1680 y provocaron una oleada de efervescencia. ${ }^{41}$ Según el testimonio del jesuita Antonio de Núñez: "aun antes de ver el Decreto [sobre la frequente

39 "Tienese por probable, que basta la atrición natural. Condenada", traducción latina por Velasco, Breviloquio moral, f. 14r. "Puede alguna vez ser absuelto el que se halla en ocasión próxima de pecar [...]. Condenada", traducción latina por Velasco, Breviloquio moral, f. 16r.

40 "Es lícito, en el administrar los Sacramentos, seguir la opinión probable a cerca del valor del Sacramento, dexada la más segura [...]. Condenada", traducción latina por Velasco, Breviloquio moral, f. 12v. El término de valor remitía a sustancia o componente, como el agua bautismal o la ostia.

41 "Miercolés 27 [...], Pregonóse edicto del Santo Oficio, con sesenta y cinco proposiciones condenadas por el Sr. Inocencio XI [...] vino un decreto acerca de la comunión cuotidiana”; Robles, Diario, t. I, p. 279. "Domingo 7 [de abril], se leyeron los edictos del Santo Oficio, prohibiendo el libro intitulado Maravilla de la Gracia; y sesenta y cinco proposiciones condenadas"; RoBLEs, Diario, p. 281. También: "Su pública intimación en esta Corte de México, que se hizo en las Iglesias, y lugares públicos en siete de abril, del año de 1680". Velasco, Breviloquio moral, f. 1r. 
comunión], leerlo, ni entenderlo, se esparció voz común, y fama pública de que avía venido una Bulla (assi le llamaban) contra la frequente Comunión [...], con otras mil chimeras; [...] volando en alas del vulgo, y particulares no plebeyos”. ${ }^{42}$

En su vertiente sacramentaria, los decretos papales sirvieron para plantear la problemática pastoral. La nueva severidad curial sobre el tema no era ignorada por entonces por algunos sectores bien informados del virreinato, como los jesuitas. En 1676, el prepósito de la Casa Profesa, Francisco Carboneli, había recomendado a sus subordinados que limitaran la comunión de los seglares. ${ }^{43}$ Para defenderlo frente a las acusaciones inquisitoriales, el 30 de junio de 1677, el general Oliva había señalado, sin gran éxito, al provincial Ximénez: "Sepa VR y hágalo saber a todos, q[ue] el Papa [Inocencio XI] no quiere, q[ue] se introduzga la comunión de cada día, ni q[ue] la enseñen, o aconsejen los n[uest]ros a personas seculares". ${ }^{44}$ Sin embargo, a diferencia del antiprobabilismo, estas nuevas exigencias de rigor sacramentario no tenían promotores organizados en la Nueva España, fuera de iniciativas personales y puntuales. Los decretos papales introdujeron pues una presión inédita sobre las prácticas pastorales del conjunto clerical. De hecho, la moderación de la comunión se enfrentaría a adversarios determinados.

En su vertiente antiprobabilista, los decretos funcionaron como un catalizador. Primero, permitieron a actores ya involucrados, como los dominicos, reconfigurar sus estrategias rigoristas. Fortalecidos por la curia, las autoridades provinciales dominicas asumieron de ahora en adelante una publicidad constante. Además de su susceptibilidad particular en materia de indulgencias, los dignatarios de la orden se dedicaron

42 NúÑ̃z, Explicación literal y sumaria, p. 2.

43 Carboneli fue al parecer víctima de un complot interno, pues en paralelo a su denuncia a la Inquisición por unos de sus correligionarios, llegan muchas críticas internas a su gestión al general jesuita. ARSI, México 3, 82r., 83r., 92v. 44 ARSI, México 3, 108r. 
sistemáticamente a validar con sus aprobaciones toda publicación novohispana que, de una manera u otra, vehiculara contenido severo (véase el cuadro 1). Segundo, los decretos papales alentaron la afirmación de nuevos sectores, tanto religiosos como laicos. En el sector clerical, los franciscanos descalzos se sumaron públicamente a los dominicos. Por el mes de mayo de 1681, el descalzo Tomás de Velasco publicaba en México, con el apoyo de sus superiores, un tratado explicativo del decreto papal de mayo de $1679 .{ }^{45}$ Se trató de la primera obra rigorista, de orden antiprobabilista, editada en la Nueva España (véase el cuadro 2). Además de promover las condenaciones de Inocencio XI, Velasco hizo explícito desde el comienzo su rechazo del probabilismo:

De este viciado principio [la ignorancia de los mortales] vienen varios, y multiplicados daños: [...] entre los quales no es el menor, ver la mayor parte de los hombres gobernados de la opinión, y engañados de los sentidos, juzgando las cosas, no por lo que son, sino por lo que parecen. Donde siendo al hombre natural el deseo de saber, y no pudiendo dar con la verdad, como es en sí, se llega a ella raciocinado por probabilidad, que es a sentir a la cosa, por motivos racionales, aunque con temor de lo contrario. Donde a veces obscurecida del error la razón, o turbada de la passion, y aun a veces hasta ser conmovida de la debida rectitud, produce efectos, que infaman a la misma razón, quedando sola la razón en este estado, para defender sin razones. ${ }^{46}$

45 Tomás de Velasco era originario del Real de Minas de Pachuca. Para la fecha del tratado, nos basamos en los paratextos para su impresión. El más temprano es del 22 de marzo de 1681. El apoyo institucional aparece en la aprobación para la licencia de la orden, pues fue suscrita por el definidor de la provincia en persona, Bartolomé de Medina.

46 Velasco, Breviloquio moral [f. 7v]. En paralelo, promovió el probabiliorismo: "Luego no se ha de excusar de pecado, el que electa la probable (en ese casso) dexa la más segura", Velasco, Breviloquio moral, f. 13r.; "Porque con razón pecara el que obrara con opinión probable, dexando la 
En su iniciativa, los franciscanos descalzos obtuvieron naturalmente el apoyo dominico con la aprobación de un miembro destacado, el exrector del Portacoeli José de Herrera. La obra de Velasco asoció también a otra personalidad importante de la intelectualidad eclesial del virreinato, el profesor de Vísperas de Teología de la universidad capitalina, el doctor Antonio de Gama. Sobre todo, el tratado de Velasco fue fomentado activamente por actores seglares: la empresa editorial de Paula de Benavides, viuda de Calderón. La publicación de la obra fue directamente financiada por la empresaria. ${ }^{47} \mathrm{Si}$ bien el franciscano descalzo y sus apoyos clericales actuaban por convicción, ésta se implicó probablemente más por oportunismo económico. Tal como lo señaló un comentarista en mayo de 1684, la oferta de literatura rigorista era todavía baja en el virreinato. ${ }^{48}$ En enero de 1681, algunos meses antes de la salida de la obra de Velasco, la propia Benavides y su rival Rodríguez Lupercio sólo tenían en sus escaparates obras de probabilistas, representantes notorios de la cultura teológica indulgente. ${ }^{49}$ Para Benavides, la edición de Breviloquio moral práctico de Velasco constituyó pues una inversión financiera, sometida a la lógica de la ganancia. Por medio de ella, la progresión de una moral severa en la Nueva España no descansó únicamente en la dinámica de convicción sino también sobre consideraciones de rentabilidad. ${ }^{50}$

más probable”. Velasco, Breviloquio moral, f. 34v. El tono de la obra es claramente combativo, por ejemplo: "Lo qual es grave absurdo contra razón y prudencia”, f. 13r.; “Es error intolerable”, 14r.

47 Según el pie de imprenta: "Con licencia en México, por la Viuda de Bernardo Calderón. A su costa, 1681”.

48 Sánchez lamentó en mayo de 1684: "Muchos authores han escripto acerca de estas proposiciones condenadas, cuyos escriptos no llegan con tanta abundancia a esta nuestra Región”. RodRíguez, Explicación [f. 6r.].

49 Como los máximos representantes del probabilismo, Antonio de Diana, Antonio de Escobar o Busembaum. AGN, Inquisición, vol. 645, exp. 3.

50 La implicación directa de Benavides en la publicación de Velasco matiza el papel atribuido en general por la historiografía a los impresores novohispanos. 
Cuadro 1

PRESENCIA DOMINICA EN LIBROS DE TENDENCIA RIGORISTA PUBLICADOS EN EL VIRREINATO (1680-1700)

\begin{tabular}{|c|c|c|c|}
\hline Nombres & $\begin{array}{c}\text { Cargo } \\
\text { ostentado }\end{array}$ & Origen & Generación \\
\hline José de Herrera & Rector & México & Profesión 1654 \\
\hline Francisco Sánchez & $\begin{array}{l}\text { Procurador } \\
\text { general }\end{array}$ & $\begin{array}{l}\text { ¿México/ } \\
\text { Valladolid? }\end{array}$ & $\begin{array}{l}\text { Profesión } \\
1634 / 1644\end{array}$ \\
\hline Francisco Sánchez & Exprovincial & Idem & Idem \\
\hline Juan Bautista Méndez & $\begin{array}{l}\text { Catedrático } \\
\text { Univ. }\end{array}$ & Novohispano & $\dot{e} ?$ \\
\hline Juan del Castillo & Rector & ¿? & $\dot{2} ?$ \\
\hline $\begin{array}{l}\text { Navarro de San } \\
\text { Antonio }\end{array}$ & Rector & México & Profesión 1671 \\
\hline Idem & Idem & Idem & Idem \\
\hline
\end{tabular}

\begin{tabular}{|l|l|c|}
\hline \multicolumn{1}{|c|}{ Nombres } & \multicolumn{1}{|c|}{ Libro aprobado } & Año \\
\hline José de Herrera & Breviloquio moral práctico & 1681 \\
\hline Francisco Sánchez & Explicación de las 65 propo. & 1684 \\
\hline Francisco Sánchez & Vida espiritual común & $1689 / 1690$ \\
\hline Juan Bautista Méndez & Compendio de las excelencias & 1690 \\
\hline Juan del Castillo & Compendio del despertador & 1695 \\
\hline $\begin{array}{l}\text { Navarro de San } \\
\text { Antonio }\end{array}$ & Despertador republicano & 1699 \\
\hline Idem & Despertador republicano & 1700 \\
\hline
\end{tabular}

Con el Breviloquio, Benavides asumió una verdadera labor editorial, que la alejaba de la función pasiva de simple impresora. Para un comportamiento similar, véase también la publicación por Guillena Carrascoso, en 1696, de la tercera parte de Luz de verdades católicas de Martínez de la Parra. 


\section{Cuadro 2}

RIGORISMO EDITORIAL DEL SECTOR FRANCISCANO DESCALZO (1681)

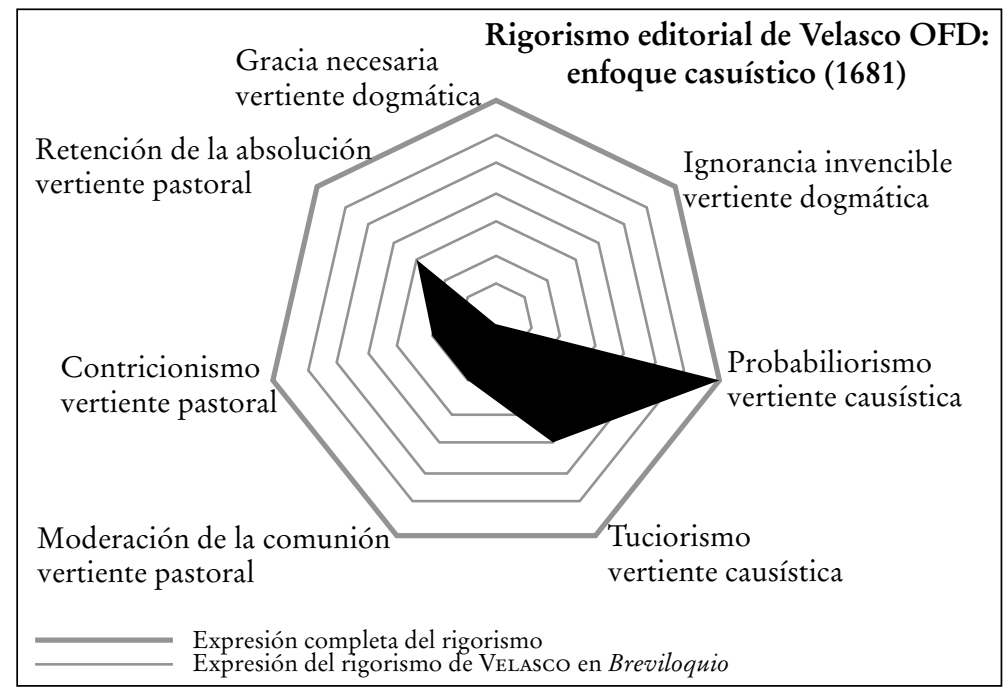

Elaboración propia con base en Breviloquio moral. La escala es de 0 a 7 para los siete ejes rigoristas.

La nueva severidad se expandió inicialmente en la Nueva España desde focos dominicos sobre la casuística. Se trató entonces de un antiprobabilismo clásico y moderado, que se concentraba principalmente en los abusos del probabilismo y sus efectos negativos sobre la administración de las consciencias. La polémica de 1676, provocada por la difusión de la obra del dominico Sánchez, y su lógica confrontacional modificaron luego este escenario inicial. En torno a la cuestión de las indulgencias, colocaron en el centro de los debates intelectuales para los sectores clericales la oposición probabilismo-antiprobabilismo. Además, radicalizaron a los actores rigoristas. Por una parte, empujaron a los dominicos hacia un tuciorismo radical y militante en materia de indulgencias, que llegó a distinguirlos de 
sus propios correligionarios en la orden. Por otra, prepararon la participación de nuevos militantes de la severidad. Finalmente, en 1680, la publicación de los decretos papales constituyó otro momento decisivo. Desde su posición de autoridad, Inocencio XI introdujo exigencias inéditas de severidad pastoral y legitimó las corrientes antiprobabilistas, las cuales empezaron a expresarse por las prensas. En esas condiciones, para finales de 1681, la cultura indulgente se vio incluso debilitada. Durante los años siguientes, sus defensores en el virreinato se organizaron para tratar de refrenar la progresión del rigorismo.

\section{LA RESPUESTA INDULGENTE O LA TENTATIVA DE CONTENCIÓN}

DEL RIGORISMO EN LA NUEVA ESPAÑA (1682-1698)

El 23 de noviembre de 1682, Francisco de Aguiar y Seijas entró oficialmente en funciones como arzobispo de México. Originario de Galicia, inauguraba un reinado arquiepiscopal de alrededor de 15 años y abría al mismo tiempo un ciclo de desaceleración para el rigorismo en el virreinato. Tributario de una formación clásica, el nuevo prelado era en efecto un defensor de la teología y pastoral tridentina tradicional..$^{51}$ En contra de las nuevas exigencias de severidad, seguía promoviendo, por ejemplo en relación con la penitencia, una comprensión indulgente de los feligreses. ${ }^{52}$ La observación de los progresos del rigorismo y su reciente legitimidad obtenida directamente del papa fueron

${ }^{51}$ Sobre la formación de Aguiar y Seijas, véase Quintero ÍñIguez, "La infancia de un obispo".

${ }^{52}$ Según su biógrafo, "ordinariamente se valía de medios suaves, y blandos [para el remedio de los pecados], por ser su Ill[ustrisi]ma de natural muy benigno", LezAmis, Breve relación [f. 23v.]. También sobre la penitencia: "haciéndose con su buen modo dueño de los corazones de todos". Lezamis, Breve relación [f. 24r.]; "al que se llamaba metido en tales pecados, y hazerle mucha honra, y tratarle con mucha cortesía: que aunque su Illma era muy cortés con todos, pero con especialidad se mostraba con quienes quería ganar para Dios...". Lezamis, Breve relación [f. 24r.]. 
sin duda materia de descontento y preocupación para el nuevo prelado. Si bien aceptó el principio de retención de la absolución para los reincidentes, Aguiar y Seijas permanecía apegado al probabilismo, a la comunión frecuente y a la atrición. De manera paradójica respecto a su historiografía, ${ }^{53}$ se dedicó rápidamente a tratar de limitar, dentro de su jurisdicción, los avances de la moral severa hasta el punto de convertirse en el principal baluarte de la cultura indulgente en la Nueva España. Su política contra el rigorismo iba a conocer dos fases: ofensiva primero y defensiva después.

Desde su posición de autoridad, el nuevo prelado procedió inicialmente de dos maneras complementarias. Por un lado, prohibió la publicación de las tesis rigoristas en su arzobispado para no repetir el precedente reciente de la obra de Velasco. Por otro, erigió como doctrina normativa para su clero un corpus probabilista e indulgente, que tendió a limitar las nuevas exigencias papales. En 1682, apenas unos meses después de su llegada a México, Aguiar y Seijas otorgó su apoyo público a una obra del franciscano José de Ledesma destinada a los eclesiásticos. ${ }^{54}$ Si bien integraba la retención de absolución, el texto de Ledesma incitaba claramente a la frecuente comunión. ${ }^{55}$ Luego, dos años después, en 1684, el arzobispo hizo publicar en la capital por

${ }^{53}$ La historiografía del arzobispo se ha construido mayormente con base en la valoración de su relación con sor Juana, lo cual ha dado a Aguiar y Seijas un matiz negativo. Por ejemplo: MAZA, Sor Juana Inés de la Cruz ante la bistoria; Paz, Sor Juana Inés de la Cruz o Las trampas de la fe; Bravo Arriaga, La excepción y la regla.

${ }^{54} \mathrm{El}$ apoyo del arzobispo se manifestó públicamente por medio de una concesión de indulgencia por la lectura de la obra.

55 Nos basamos en la reedición de 1696. Ledesma, Silvos, f. 5r. Para la retención de absolución: "Cómo [...] no les suspenden la absolución dando tantos indicios, de que no fue bueno su propósito, pues luego lo quebrantaron". Ledesma, Silvos, f. 4v. Para la frecuente comunión: "Porque no le aplicas, que frequente el Comulgar, pues en el Altar dexé yo la medicina, y remedio mayor del pecador, para conservarlo en gracia y encaminarlo a la Gloria?”. LEDESMA, Silvos, f. 5 r. 
medio de su provisor, Diego de la Sierra, una relectura permisiva de los decretos de Inocencio XI en su vertiente casuística, redactada por el carmelita navarro Raimundo Lumbier. ${ }^{56}$ En términos de probabilismo, el regular reconocía el marco del debate: "Es en estos tiempos batalla muy reñida, si se puede en conciencia seguir la opinión menos probable en qualquier materia [...] quando se puede seguir la más probable. Una, y otra sentencia tienen en estos tiempos grandes defensores". ${ }^{57}$

Pero Lumbier optaba claramente por la solución probabilista, circunscribiendo las exigencias papales de probabiliorismo al valor del sacramento y dejando fuera al resto de la casuística. ${ }^{58}$ En paralelo, el carmelita reactivaba algunos análisis probabilistas muy polémicos, como respecto al homicidio, el cual justificaba por ejemplo en caso de atentado al patrimonio. ${ }^{59}$

Por 1684, la ofensiva contra la reacción severa liderada por Aguiar y Seijas captó además a unos aliados de peso: un sector jesuita. En 1676, los jesuitas ya se habían enfrentado al antiprobabilismo dominico en el virreinato y, dentro del espacio transatlántico, se habían convertido en defensores acérrimos de la corriente indulgente frente a los ataques rigoristas. En la arquidiócesis, su apoyo vino en particular de un dignatario respetado: Antonio de Núñez Miranda. Probabilista convencido, el jesuita disponía del prestigio personal y de la amplitud social necesaria para difundir un alegato en favor de la cultura

56 Mano derecha del arzobispo, Sierra fue el destinatario de la publicación. Lumbier, Noticia de las sesenta y cinco proposiciones.

57 Lumbier, Noticia de las sesenta y cinco proposiciones, f. $24 \mathrm{r}$.

58 Por ejemplo: "Mi parecer es, mientras su Santidad no declare lo contrario, que se puede usar de opinión probable (como sea sólida y ciertamente probable) porque esta es la sentencia común de los Doctores". Lumbier, Noticia de las sesenta y cinco proposiciones, f. $10 \mathrm{v}$.

59 “Assiento lo primero [...] que por defender la hazienda, si no ay otro camino, es lícito quitarle al invasor la vida. La razón es, porque la hazienda es los medios con q un hombre ha de vivir; y por esso se llama la segunda sangre.” Lumbier, Noticia de las sesenta y cinco proposiciones, f. 55r. 
teológica de la indulgencia..$^{60} \mathrm{~A}$ finales del año de 1684 , se suscribió a la defensa de la pastoral frecuente con dos textos, publicados en un solo volumen por Juan de Ribera y que volvería a editar luego separadamente en 1687 y 1690. Por medio de ellos, Núñez apoyó la administración frecuente, incluso cotidiana, de la comunión, lo cual no llevaba según él a la rutinización del sacramento sino al acercamiento con Dios. El jesuita procedió de dos maneras: práctica y técnica. En el primer texto, proporcionó un caso de aplicación con el ejemplo de su propia congregación: la Purísima. En contra del nuevo endurecimiento pastoral, subrayó el objetivo espiritual de sus miembros: "que puedan comulgar cada día, que esso desea la Purísima en sus congregantes, como el Concilio Tridentino en todos los fieles". ${ }^{61}$ En el segundo texto, el jesuita propuso una relectura del decreto de Inocencio XI sobre la administración frecuente del sacramento, con el fin de limitar su alcance. Según Núñez, el papa sólo se había empeñado en combatir algunos excesos. Contra el sentido de las directivas papales, el novohispano llegó incluso a afirmar: "consta con evidencia prudencial, y legal, que todo el [decreto] favorece a la Comunión frecuente, o quotidiana, hecha con la debida disposición". ${ }^{62}$

Pese a su envergadura, la ofensiva contra el rigorismo llevada desde el palacio arzobispal resultó no obstante limitada. Tanto fuera como dentro de la Nueva España, los partidarios

60 Para el probabilismo de Núñez: "Y como es favorable, y amplissima providencia del Señor, que aya en su Iglesia esta variedad de probabilidades opuestas, y opiniones encontradas, para que todas las consciencias varias, y genios encontrados tengan sus medios proporcionados, y medicamente aptos". NúñEz, Comulgador, y explicación mystica, f. 14r.

${ }^{61}$ NúÑEz, Comulgador, y explicación mystica, f. 9v.

${ }^{64}$ NúÑEZ, Explicacion literal y sumaria, p. 28. También "Esta ya no solo es [el decreto], favorecer, y aplaudir la Comunión frequente: sino encargarla, patrocinarla, y defenderla". NúÑEZ, Explicacion literal y sumaria, p. 35. El texto fue denunciado a la Inquisición por dominicos de Santiago de Guatemala en noviembre de 1695. AGN, Inquisición, vol. 531, exp. 1. 
de la severidad se beneficiaban de una dinámica de progresión rápida y convergían desde sus esferas respectivas. A nivel del espacio transatlántico, las presiones provinieron de instituciones supraimperiales: la institución inquisitorial y las instancias centrales de órdenes regulares. El 25 de enero de 1684, el Santo Oficio puso en el Índex la obra de Lumbier que Aguiar y Seijas acababa de promover. ${ }^{63}$ En México, la noticia llegó probablemente poco tiempo después de su publicación capitalina y, para el arzobispo, se trató de un fuerte desaire público en su combate contra el rigorismo. Luego, en 1686, las autoridades franciscanas en Roma declararon el probabiliorismo como doctrina oficial de su tercera órden. En el Imperio hispánico, la directiva llegó hacia 1689.64 En la Nueva España, fisuró el frente de la cultura indulgente al revelar nuevos promotores de la severidad dentro de espacios franciscanos calzados que hasta entonces se habían manifestado en favor del probabilismo. En paralelo, el generalato de la Compañía de Jesús recayó, en julio de 1687, en un ferviente promotor del probabiliorismo, Tirso de González, quien llevó ante sus subordinados una política agresiva de adhesión al antiprobabilismo. ${ }^{65}$

A nivel del virreinato, las presiones eran similares. Lejos de haber sido callados por Aguiar y Seijas, los partidarios del antiprobabilismo se limitaron a replegarse en Puebla, que se convirtió en obispado refugio para los rigoristas. Durante el año de 1684 , los franciscanos descalzos retomaron su campaña antiprobabilista con un segundo libro, publicado esta vez en las prensas poblanas. Su autor era un correligionario cercano a

\footnotetext{
${ }_{63}$ Bujanda, Index des livres interdits, p. 564.

${ }^{64}$ Firmada en 1686 por Inocencio XI, la regla pasó a las provincias españolas e indianas hacia 1689. Préclin, Histoire de l'Église, p. 495.

${ }^{65}$ GAY, "Affinités (s)électives. Innocent XI et Tirso González de Santalla", pp. 113-144.
} 
Velasco, Matías de Rodríguez. ${ }^{66}$ Respaldado por sus superiores y los dominicos, el regular se dedicó a su vez a criticar abiertamente los excesos del probabilismo para promover el probabiliorismo como único sistema justo para la casuística. ${ }^{67}$ En 1691, el descalzo fue seguido por los dominicos Francisco Sánchez y Nicolás de Merlo con otras dos obras poblanas decididamente antiprobabilistas. Retomando la cuestión de las indulgencias, los dos hombres desarrollaron de nuevo un discurso agresivo hacia la doctrina de las opiniones probables, además de su tuciorismo sacramentario. ${ }^{68}$

Frente a la tenacidad de los rigoristas y ante los escasos resultados de su política, Aguiar y Seijas se conformó durante algunos años con mantener la proscripción de las tesis rigoristas en su jurisdicción. Sin embargo, a comienzo de 1694, el prelado trató de aprovecharse de un cambio en la coyuntura curial para reactivar, por segunda vez, su combate contra la moral severa en México. En agosto de 1689, la muerte de Inocencio XI había llevado a la entronización de Alejandro VIII, quien había dado un soplo de aire fresco a los sectores indulgentes en todo el ámbito católico. Menos severo que su predecesor, el nuevo papa les había concedido, además, en diciembre de 1690, la condena de 31 proposiciones de moral severa. Dentro del panorama del rigorismo novohispano, enfocado en la casuística y en menor medida en la pastoral, las proposiciones condenadas no tenían mucho alcance por ser mayoritariamente de teología dogmática. Sólo las III y XXIII proposiciones podían coincidir eventualmente con los debates en el virreinato, aunque estaban lejos de corresponder, por su carácter radical, a posiciones defendidas

\footnotetext{
${ }^{66}$ Rodríguez declaró: “mi amantissimo Maestro el P.F. Thomas de Velasco sirviéndome como antorcha”. RodríGuez, Explicación [f. 9r]

${ }^{67}$ Según su superior, el definidor José de Veedor: "por razón de buscar en este tratado el Author entre opiniones la más segura, para la mayor seguridad de las consciencias, conviene su impresión". RodRíGUEz, Explicación [f. 4v.]. 68 SÁnchez, Thesoro regvlar; MerLo, Espejo de Indulgencias.
} 
localmente. La III proposición promovía el tuciorismo para toda la casuística, mientras que la XXIII exigía como condición para la comunión un amor puro a Dios. ${ }^{69}$ Para el arzobispo, no obstante, si bien las interdicciones papales no tenían repercusiones prácticas, exponían a la mirada pública la nueva desconfianza curial hacia las corrientes severas. Sobre todo, en su contexto de enfrentamiento con los rigoristas, funcionaban como un contragolpe. A comienzo del año de 1694, impulsó pues la publicación de la obra de un probabilista notorio, el capuchino navarro Jayme Corella, quien comentaba con satisfacción las proposiciones condenadas. ${ }^{70}$

Luego, siete meses después, el prelado prolongó su campaña tratando, con la ayuda de Antonio de Núñez, de rehabilitar la figura de Lumbier, cuya prohibición inquisitorial reciente había desacreditado en la capital. Los dos eclesiásticos se asociaron para reeditar en México una antigua obra pastoral del carmelita, de tono bastante exigente. ${ }^{71}$ Si seguía suscribiéndose al

69 "No es lícito seguir la opinión [...] probabilísima entre las probables, condenada"; Corella, Noticia, censura, impugnación, p. 7. "Del mismo modo han de ser apartados de la Sagrada Comunión aquellos, que no tienen amor purissimo de Dios, libre de toda mezcla. Condenada"; Corella, Noticia, censura, impugnación, p. 31.

70 Aguiar y Seijas firmó él mismo la licencia del ordinario. La única fecha indicada es la del virrey, para su licencia, dada el 8 de enero de 1694. Sobre el probabilismo de Corella: "Como en esta vida no podemos, por nuestra cortedad, alcançar la verdad objetiva de todas las cosas, ni la certidumbre de su bondad, o malicia, es forçoso discurrirla por principios, por efectos, por razones, por autoridad: y como estas cosas no sean infalibles en todo, por esso ha avido, y ay tantos opinamientos: y siendo probable, y bien fundado, es preciso se conceda por licito el seguirlo". Corella, Noticia, censura, impugnación, p. 8.

71 Según la portada, Núñez dio a la estampa la obra "por orden, y con mandado de su Ilustrissima el Senor Arçobispo", quien concedió además "40 días de Indulgencia a qualquiera persona de los interesados en la materia por cada vez, que leyese algún Parrapho". Lumbier, Destierro de ignorancias [portada]. La primera edición de la obra sería de 1676, en Zaragoza: Díaz, Bibliografía, t. XIII, p.699. 
probabilismo, el texto escogido manifestaba una firmeza indiscutible en términos de disciplina religiosa que contrastaba con la precedente obra de Lumbier. Tanto para el arzobispo como para el jesuita, el objetivo era liberar al autor de las acusaciones de mansedumbre y sobre todo señalar que la cultura teológica tradicional no llevaba a tolerar los pecados. Desgraciadamente para los dos hombres, esta segunda campaña no funcionó tampoco. Nuevamente, la presión rigorista era demasiado fuerte, hasta el punto incluso de socavar la prescripción impuesta por el prelado a su jurisdicción. Tanto para la vertiente pastoral como para la vertiente casuística del programa rigorista, nuevos actores seguían apareciendo.

En la vertiente pastoral, el Tribunal inquisitorial de México empezó a asumir progresivamente las nuevas exigencias de severidad. Obligados en gran medida por Inocencio XI, cuyo decreto de mayo de 1679 había sido convalidado por el Santo Oficio, los inquisidores prestaron una atención inédita a la cuestión de los sacramentos, en particular a la comunión, a partir de finales de la década de 1680. De hecho, este nuevo interés fue detectado e instrumentalizado rápidamente por dos facciones clericales en posiciones de inferioridad en sus instituciones para deshacerse de adversarios poderosos..$^{72}$ En 1689, un pequeño grupo de franciscanos denunció a su comisario general de las provincias de Nueva España, Juan de Luzuriaga, por supuestos excesos en la administración de la comunión a una fiel. ${ }^{73}$ En febrero de 1693, el procedimiento se repitió en la provincia ignaciana. Un grupo jesuita, dirigido por Martin del Prado, trató

\footnotetext{
72 Lo explicitó uno de los acusadores: "siempre ha estado prohibido en la mexor theología, y últimamente lo declara por caso de la Santa Inquisición la Santidad de Inocencio Undécimo, según muchos autores, aunque el decreto no dice que es caso de Inquisición”. AGN, Inquisición, vol. 688, exp. 3, f. 349r. ${ }^{73}$ La resolución se dio en 1690. Los inquisidores concluyeron: "no se halla en ella [la denuncia] cossa sustancial provada”. AGN, Inquisición, vol. 673, exp. 1, f. 41 r.
} 
de desembarazarse de los rectores de dos colegios poblanos, Tomas de la Xara y Martín Ramales, con base en acusaciones de abusos en los sacramentos de comunión y penitencia. ${ }^{74}$

En su vertiente casuística, la moral severa captaba también nuevos partidarios. Después de los dominicos y de los franciscanos descalzos, algunos franciscanos calzados en la provincia del Santo Evangelio de la Nueva España se asociaron a la promoción del antiprobabilismo con la llegada inesperada al poder de un nuevo provincial. Desde hacía décadas, la provincia franciscana conocía disensiones entre tres facciones distintas que se peleaban para el directorio provincial: novohispanos (criollos), peninsulares ordenados en la Nueva España (hijos de provincia) y peninsulares ordenados en España. ${ }^{75}$ Para frenar las tensiones, se aplicaba desde 1626 la ternativa, la rotación sucesiva de las facciones al provincialato. En 1694, ésta tocaba normalmente al grupo novohispano, pues los precedentes provinciales habían sido el gallego José Sánchez (1688-1691) y el hijo de la provincia Diego Truxillo (1691-1694). ${ }^{76}$ Sin embargo, el vasco y comisario general Juan de Capistrano maniobró para reclutar en su red de clientes a un novohispano, Clemente de Ledesma, y presentarlo como candidato criollo. ${ }^{77}$ Mediante esta estratagema, Ledesma fue elegido por primera vez para el provincialato en el capítulo del 24 de abril de $1694 .{ }^{78}$ Con unos 50 años, el franciscano había

${ }^{74}$ AGN, Inquisición, vol. 688, exp. 3, f. 347-418. Al parecer, la denuncia tampoco dio resultados.

75 Sobre el conflicto véase Rubial, "Votos pactados", pp. 67-71.

76 Para el acceso al provincialato de ambos, véase Robles, Diario, II, p. 158, p. 226. Para el origen de Sánchez: AGN, Inquisición, 1279, exp. 47. Para el de Truxillo: Libro de profesiones, p. 14.

77 Capistrano se registró para su embarque a la Nueva España el 6 de junio de 1689. AGI, Contratación, 5451, N. 51. Ledesma fue hijo de Eugenio Flores de Ledesma y de Josefa Arfian. Ingresó en la orden en 1658.

${ }^{78}$ Ledesma dedicó luego una obra al comisario y señaló: "No digo esto por que (sin mérito) me elevó la generosa mano de VPMR a la Prelacía en que me veo". Ledesma, Despertador de noticias [f. 4v.]. En el capítulo siguiente, 
gestionado en México durante casi una década la tercera orden de la institución, rama franciscana seglar cuya regla había sido modificada por Inocencio XI a favor del probabiliorismo. ${ }^{79} \mathrm{Su}$ inesperada elevación al provincialato como consecuencia de las intrigas internas dentro de la orden trajo pues como resultado la promoción de las posturas rigoristas entre miembros de la provincia.

Al momento de su elección, Ledesma conservaba en sus papeles un largo manuscrito, de un antiprobabilismo moderado, que actualizaba la mayoría de las directivas severas de Inocencio XI y que trató rápidamente de publicar. Siguiendo al papa, el franciscano defendía la obligación del probabiliorismo para la substancia de los sacramentos, la cual no podía en absoluto depender de opiniones que no fuesen las más seguras. ${ }^{80}$ Promovía también el estricto tuciorismo para cuestiones debatidas, como el homicidio. ${ }^{81}$ Ledesma equilibraba no obstante este rigorismo casuístico con una moderación. Primero, su probabiliorismo se detenía ante el imperativo papal de la substancia

de 1696, la faccíon criolla manifestó su inconformidad. Rubial, "Votos pactados", p. 69.

79 De 1684 a 1690 , fue comisario visitador de la tercera orden franciscana. Iguíniz, Breve historia, p. 204. Su dedicación a la tercera orden aparece también en sus dos primeras obras que público en 1689 y 1690. Para la regla de la tercera orden: Préclin, Histoire de l'Église, p. 495.

80 "El Ministro no puede elegir, ni usar en la administración de los Sacramentos de opiniones tan solamente probables del valor de los Sacramentos, dexando la más segura: Ni cerca de la materia, baptizando con agua rosada, ni otra de las aguas artificiales, que son materias dudosas..."; Ledesma, Despertador de noticias, p. 21. También: "Porque usando en todo, o en parte de opiniones tan solamente probables del valor de los Sacramentos, y dexando las más seguras, se les haze manifiesto agravio, poniendolos en peligro de nulidad". Ledesma, Despertador de noticias, p. 23.

81 "No es lícito el homicidio en ningún género de estado, ni al Religioso, ni al Clérigo, ni al Secular, antes si qualquiera de estos peca mortalmente matando a otro"; LeDESMA, Despertador de noticias, p. 222. También: "No es licito matar al ladrón"; Ledesma, Despertador de noticias, p. 224. 
de los sacramentos y no se extendía a los criterios de la penitencia, los cuales dejaba al juicio de los confesores. Segundo, el nuevo provincial se cuidaba de atacar frontalmente al probabilismo, a diferencia de sus predecesores dominicos y descalzos. Se limitaba a condenar solamente algunos excesos clásicos, como su carencia de fundamento en algunos casos: "Porque es muy peligroso practicar las opiniones solo porque están en libros impresos, siendo assi, que ni la Imprenta, ni la censura de quien aprobó el libro dan probabilidad a las opiniones, si ellas no tienen fundamentos suficientes, solidos, y bastantes: Luego la opinión no debe tenerse por probable solo por q se halla impressa en el libro". ${ }^{82}$

La moderación de Ledesma, su estricto legalismo papal, eran en gran parte estratégicos, pues el franciscano no dudaría en aconsejar más tarde la aplicación del probabiliorismo a toda la casuística (véase el cuadro 3). Le sirvieron para acercarse al arzobispo Aguiar y Seijas por medio de dos clérigos muy cercanos al prelado y que conocía: Juan de Pedroza y Manuel Muñoz de Ahumada. ${ }^{83}$ Gracias a su intermediación, Ledesma obtuvo la licencia de publicación, a pesar de que su postura teológica no concordaba con las propuestas no rigoristas del prelado. A comienzos de 1695, su obra Dispertador de noticias de los Santos Sacramentos se encontraba en las librerías. Destinada a un gran éxito, la publicación significó la entrada de los hermanos menores en la promoción de la moral severa y su autor se iba a convertir en algunos años en la figura principal del probabiliorismo

82 Ledesma, Despertador de noticias, p. 32.

${ }^{83}$ Ledesma era cercano a dos clientes del arzobispo: Juan de Pedroza y Manuel Muñoz de Ahumada. En octubre de 1685, Aguiar y Seijas recomendó a Muñoz de Ahumada a la corona. AGI, Indiferente, 210, N.21, f. 2r. Sobre la cercanía entre Pedroza y el arzobispo, Lezamis, Breve relación, p. 37, p. 44. Ambos eclesiásticos redactaron una aprobación para Ledesma. Pedroza en particular señaló: “estimo muchos años ha a su autor”. Ledesma, Compendio del despertador de noticias [f. 6r.]. 
franciscano en la Nueva España. Sobre todo, si bien por su moderación se trataba de una obra conciliadora, el Dispertador de noticias asestó un primer golpe a la prohibición de las tesis rigoristas en vigor desde hacía más de 10 años en la capital.

\section{Cuadro 3}

EVOLUCIÓN DEL RIGORISMO DE CLEMENTE DE LEDESMA

(1689-1700)

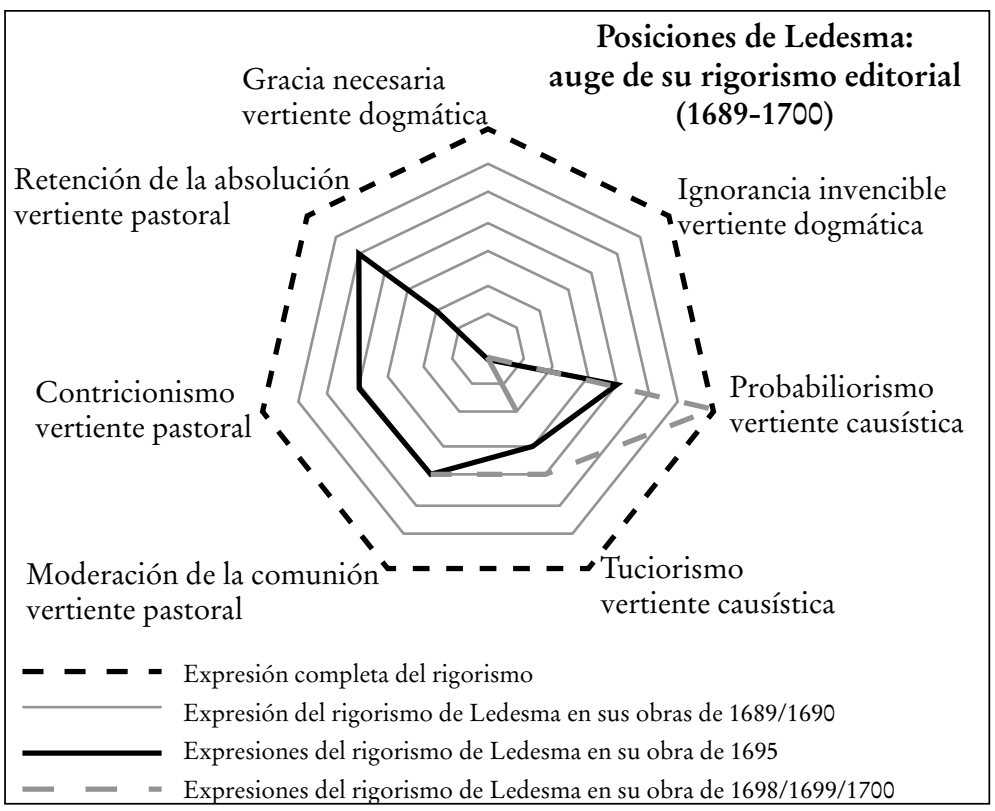

Elaboración propia.

VICTORIA DE UN RIGORISMO MODERADO: PROBABILIORISMO Y SEVERIDAD SACRAMENTARIA (1698-1700)

El 17 de febrero de 1695, Antonio de Núñez falleció en México. Tres años más tarde, el 14 de agosto de 1698, Aguiar y Seijas murió a su vez después de varios episodios de enfermedad que 
lo habían debilitado. Para los adversarios del rigorismo, ambos decesos significaron la pérdida de dos campeones de la cultura indulgente que se habían implicado públicamente contra la moral severa en el virreinato. En particular, el fallecimiento del prelado relanzó el avance del rigorismo. Por una parte, el Santo Oficio continuó involucrándose en la aplicación de la política pastoral de Inocencio XI. Por otra, el antiprobabilismo novohispano se expresó con un nuevo vigor en la capital desde mediados de 1698.

En la vertiente pastoral de la reacción severa, los funcionarios inquisitoriales siguieron impulsando el nuevo endurecimiento del acceso a los sacramentos para los feligreses. ${ }^{84}$ Además de su atención a la administración de la comunión, recibieron en octubre de 1699 una denuncia por parte de un dominico respecto a una obra muy esparcida, el catecismo del jesuita Jerónimo de Ripalda, la cual se suscribía a la atrición natural para la penitencia. ${ }^{85}$ La obra de Ripalda era anterior por más de sesenta años a los nuevos mandamientos de severidad y no se trataba de una obra polémica. Sin embargo, los inquisidores la sometieron enseguida al análisis de sus calificadores, el franciscano Nicolás Masías y el dominico Bartolomé de Navarro de San Antonio, quienes dieron pareceres opuestos. Pero como resolución, el inquisidor Deza y Ulloa se alineó en la perspectiva severa y aconsejó la modificación de la proposición incriminada.

En la vertiente casuística de la severidad, el antiprobabilismo se expresó más abiertamente en la capital luego del fallecimiento

${ }^{84}$ A nivel del programa rigorista casuístico, parece que hubo discrepancias internas entre inquisidores. En 1695, un libro del jesuita Moya, probabilista convencido, fue denunciado al tribunal capitalino. Pese a que tres calificadores mercedarios solicitaron la confiscación del libro por ser "más en favor de la libertad que del precepto", el inquisidor Gómez de Mier se opuso a la medida por "no ser conforme" con las calificaciones. AGN, Inquisición, vol. 531, exp. 2. ${ }^{85}$ Sobre la denuncia del catecismo de Ripalda: AGN, Inquisición, vol. 706, exp. sin número, f. 143-155. Para otra denuncia por exceso en la comunión en 1699, AGN, Inquisición, vol. 710, exp. 3, f. 19r.-23r. 
de Aguiar y Seijas. En los años de 1698, 1699 y 1700, el franciscano Clemente de Ledesma prosiguió con su empresa editorial con tres obras nuevas. Además de promover nuevamente el legalismo papal, Ledesma extendió sutilmente el campo de aplicación del probabiliorismo, que salió del valor de los sacramentos para abarcar la evaluación de la penitencia (véase el cuadro 3). Por una parte, el franciscano lo prescribió explícitamente para los casos de aborto. ${ }^{86}$ Por otra, tendió a recomendarlo para toda la casuística. En su obra de 1698, subrayó que "De las opiniones caeteris paribus, se debe seguir la más segura, según se infiere de lo que dixo NPS Agustín". ${ }^{87}$ En 1700, escribió: “Aquí debe el Sacerdote Ministro advertir, que fuera de la administración de los Sacramentos, y fuera de otros dos casos que más abajo se expressan, se puede lícitamente seguir la opinión probable, y mejor la probabilísima entre las probables" ${ }^{88}$ En ambos casos, no se trataba de órdenes categóricas sino de recomendaciones, lo cual colocaba de nuevo a Ledesma en una posición de consenso frente a la intelectualidad religiosa novohispana. Esta perspectiva moderada, que renunciaba al enfrentamiento entre rigor e indulgencia al dejar a los confesores escoger sus probabilidades mientras que se inclinaba hacia el probabiliorismo, favoreció obviamente la difusión de las tesis del franciscano, cuyas obras conocieron un rápido éxito ante los sectores letrados. ${ }^{89}$ Sobre todo, hizo que la progresión del rigorismo saliera de la dinámica confrontacional que se había iniciado en Nueva España a finales

\footnotetext{
86 “[...] porque aquí se dessea para el Confessor lo más seguro, procure ajustarse al proverbio canonista, que dice: Que en la duda se ha de elegir la parte más segura"; Ledesma, Despertador de noticias theologicas, p. 21.

87 Ledesma, Despertador de noticias theologicas, p. 362.

${ }^{88}$ Ledesma, Despertador republicano, p. 329.

${ }^{89}$ Según sus censores. Para Martínez de la Parra en 1698: "No dudo será este tomo tan aplaudido como el primero". Ledesma 1698 [f. 3r.]; para Navarro en 1699: "ha dado tantas pruebas, y tan buenas, como es notorio", Ledesma, Despertador republicano, [f. 8v.]; para Arguello en 1700: “corrían con común aplauso", Ledesma, Despertador republicano [f. 8r].
} 
de la década de 1670, con la controversia sobre las indulgencias y los decretos de Inocencio XI, para inscribirla en un registro conciliador, a diferencia de otros espacios católicos donde el conflicto abierto se mantendría aún.

\section{CONCLUSIÓN}

Hacia los años inaugurales del nuevo siglo, la moral severa estaba instalada en la Nueva España en dos de sus ejes: casuística y sacramentaria. En la vertiente casuística, la reacción rigorista fue llevada por los dominicos del virreinato sobre la constatación clásica de los excesos de la doctrina probabilista. En 1676, la polémica sobre las indulgencias amplió luego el debate, el cual se inscribió durante algún tiempo en la esfera pública, con el intercambio de tratados o pasquines clandestinos. Sobre todo, radicalizó la posición de los dominicos de Nueva España, que asumieron una firmeza inédita y original en su orden, por medio de un tuciorismo específico sobre indulgencias. Finalmente, en 1680, la intervención supraimperial de la curia con los decretos de Inocencio XI mudó de manera duradera el equilibrio de las fuerzas a favor del rigor casuístico, pese a las tentativas de contención de un sector indulgente liderado por el arzobispo Aguiar y Seijas. En la vertiente pastoral, si bien la nueva severidad y su endurecimiento sacramentario eran conocidos en el virreinato, su aplicación progresiva difirió por algunas décadas del eje casuístico. A diferencia de éste, su primer promotor organizado fueron las instancias curiales que se apoyaron en parte sobre la institución inquisitorial para adecuar las prácticas a las nuevas normas.

La severidad novohispana del siglo XvII no parece haber incluido, en cambio, una vertiente de teología dogmática. Dos hipótesis pueden formularse para explicar este desinterés. A nivel imperial, la cultura teológica hispánica, tal como probablemente la germánica, poseía una fuerte cohesión interna con base en 
diferentes factores. A diferencia de Francia u Holanda, donde la reacción severa conoció un importante desarrollo dogmático, el espacio hispánico no experimentó por ejemplo en su mismo territorio la disidencia calvinista y sus proposiciones austeras. A nivel novohispano, algunas premisas rigoristas tenían de suyo escaso poder de convencimiento de todas maneras. El rechazo a la ignorancia invencible o la idea de que el desconocimiento involuntario de la ley divina no protegía del pecado contradecía todos los postulados construidos sobre los indígenas, los cuales no se modificarían sino hasta mediados del siglo siguiente. ${ }^{90}$ Sea como fuere, la progresión rápida durante la segunda mitad del siglo xviI de la moral severa en la Nueva España puso las bases, como para otros espacios católicos, de una nueva racionalidad. Al cuestionar la probabilidad como vía de acceso a la verdad, el antiprobabilismo en particular fue un elemento favorable para la elevación de la certidumbre como única modalidad epistemológica válida. ${ }^{91}$ Por su parte, la nueva severidad pastoral auguraba el desarrollo de una nueva consciencia, más autónoma. ${ }^{92}$

Este texto no pretende haberlo dicho todo sobre el auge del rigorismo novohispano. Primero, queda enteramente abierto a revisión tanto en términos de marco cronológico como de registro de actores por ser un simple primer acercamiento antes que un analisis definitivo. Segundo, numerosos aspectos no han sido tratados, pese a su interés. A nivel de los sectores rigoristas de la Nueva España, faltó señalar por ejemplo su carácter intergeneracional o sus orígenes regionales diversos (novohispanos, vascos, andaluces...) e insistir en la participación seglar. A nivel de sus adversarios, no se ha aludido tampoco a algunas

\footnotetext{
90 LARA, ¿Ignorancia invencible?

91 CARraud, "Morale par provision et probabilité".

92 Quantin, Le rigorisme chrétien.
} 
reacciones soterradas que merecerían un estudio detenido. ${ }^{93} \mathrm{Tal}$ como se ha presentado, el desarrollo de la reacción severa novohispana ofrece no obstante a la reflexión dos elementos de orden historiográfico. En primer lugar, recalca la importancia, para la investigación sobre el tema, de una lectura supraimperial. En efecto, el virreinato integraba un campo eclesial transatlántico que rebasaba el entramado multicéntrico del Imperio hispánico. Pioneros del rigorismo, los dominicos de Nueva España formaban parte de un grupo profesional desplegado en todo el espacio católico, con un grado muy elevado de conexión interna y una identidad corporativa fuerte. Por su parte, las políticas curiales, elaboradas desde Roma, desempeñaron un papel clave en el fortalecimiento del rigorismo novohispano, lo cual hace indispensable su consideración. En segundo lugar, el rápido auge de la moral severa en la Nueva España confirma a su nivel los análisis historiográficos recientes que señalan la pluralidad de las culturas teológicas en el virreinato. ${ }^{94}$ Lejos de suscribirse únicamente a una ortodoxia tridentina clásica y monolítica, los sectores eclesiales novohispanos promovieron programas distintos, en este caso incluso contradictorios, que llegaban a cohabitar con más o menos tensiones para conformar un panorama contrastado.

\section{SIGLAS Y REFERENCIAS}

AGI Archivo General de Indias, Sevilla, España.

AGN Archivo General de la Nación, Ciudad de México, México.

ARSI Archivum Romanum Societatis Iesus, Roma, Italia.

\footnotetext{
93 Mientras se afianzaba el programa severo, un grupo reducido de jesuitas desarrolló unas tesis inversas sobre la comunión, las cuales llegaron a promover su administración a los niños. El caso fue muy sonado en la Inquisición: AGN, Inquisición, vol. 707, exp. 1; vol. 534, exp. 5; vol. 690, exp. 5.

94 Escamilla, "Reformar la reforma".
} 
BAUstert, Raymond (comp.), Le jansénisme et l'Europe, Tubinga, Narr, 2010.

Bösel, Richard, Innocenzo XI Odescalchi, Papa, politico, committente, Roma, Viella, 2014.

Brading, David, “El jansenismo español”, en VÁzquez, 1992, pp. 187-215.

Bravo Arriaga, María Dolores, La excepción y la regla: estudios sobre espiritualidad y cultura en la Nueva España, México, Universidad Nacional Autónoma de México, 1997.

Bujanda Martínez, Jesús, Index des livres interdits, 1600-1966, Ginebra, Librairie Droz, 2002.

Callahan, William J., Iglesia, poder y sociedad en España, 1750-1874, Madrid, Nerea, 1989.

CARraud, Vincent, "Morale par provision et probabilité", en Roshdi Rashed (ed.), Descartes et le Moyen Age, París, Vrin, 1997, pp. 259-279.

Concina, Daniele, Historia del probabilismo y rigorismo: Dissertaciones theologicas, morales y críticas en que se explican y defienden de las sutilezas de los modernos probabilistas los principios fundamentales de la theologia christiana, Madrid, viuda de Manuel Fernández, 1772.

Corella, Jayme, Noticia, censura, impugnación y explicacion de las XXXI proposiciones condenadas por el santisimo Padre Alexandro Papa VIII, México, Imp. Viuda Rodríguez Lupercio, 1694.

Delumeau, Jean, L'aveu et le pardon: Les difficultés de la confession (XIII'XVIII siècle), París, Fayard, 1990.

Díaz, José Simón, Bibliografía de la literatura hispánica, Madrid, Consejo Superior de Investigación Científica, 1984, t. XIII.

Escamilla, Iván, "Reformar la reforma: Juan Pablo Zetina Infante y la polémica litúrgica e histórica por la jura del Patronato Guadalupano en Nueva España, 1737-1746”, en MarTínez LóPEZ-CANo, 2014, pp. 227-247.

Gallegos Rocafull, José, El pensamiento mexicano en los siglos XVI y XVII, México, Universidad Nacional Autónoma de México, 1951. 
GAY, Jean-Pascal, "Laxisme et rigorisme: théologies ou cultures? Deux controverses au tournant du XVII ${ }^{\mathrm{e}}$ siècle", en Revue des sciences philosophiques et théologiques, 87: 3 (2003), pp. 525-548.

GAY, Jean-Pascal, Morales en conflit, théologie et polémique au Grand siècle: 1640-1700, París, Éditions du Cerf, 2011.

GAY, Jean-Pascal, “Affinités (s)électives. Innocent XI et Tirso González de Santalla: aspirations réformistes et idéologisation du catholicisme à la fin du XVII siècle”, en BösEL, 2014, pp. 113-144.

Gómez, Anselmo, Tesoro de la sciencia moral [sin lugar], Imp. J-B de San Clemente, 1667.

Hurtubise, Pierre, La casuistique dans tous ses états: de Martin Azpilcueta à Alphonse de Liguori, Ottawa, Novalis, 2005.

IguínIz, Juan, Breve historia de la Tercera Orden Franciscana en la Provincia del Santo Evangelio de México: desde sus orígenes hasta nuestros días, México, Patria, 1951.

Lara Cisneros, Gerardo, ¿̇Ignorancia invencible? Superstición e idolatría ante el Provisorato de Indios y Chinos del Arzobispado de México en el siglo XVIII, México, Universidad Nacional Autónoma de México, 2014.

LASKe, Trilce, “Trajectoires, postures et modes d'action des homme d'Eglise en Nouvelle-Espagne (1680-1705)", tesis de doctorado, Toulouse, Université Toulouse II, 2015.

Ledesma, Clemente, Dispertador de noticias de los santos sacramentos, México, Maria de Benavides, 1695.

Ledesma, Clemente, Compendio del despertador de noticias de los santos sacramentos: que sacó a luz, y en este succinta: para los que se han de presentar de confessores, México, María de Benavides, 1695.

Ledesma, Clemente, Despertador de noticias theologicas morales, que apuntan, $y$ despiertan las letras del A.B.C. al cura, al comissario del Tribunal de Santo Officio, y al confessor, México, María de Benavides, 1698.

Ledesma, Clemente, Despertador republicano, que por las letras del A. B. C. compendia el segundo tomo de noticias theologicas morales, México, María de Benavides, 1699. 
Ledesma, Clemente, Despertador republicano, que por las letras del A.B.C. compendia los dos compendios del primero, y segundo tomo del despertador de noticias theologicas, México, María de Benavides, 1700.

Ledesma, José, Silvos con que el pastor divino avissa à todos los sacerdotes, padres, y ministros de su iglesia, y pastores de su rebaño, las graves obligaciones de tan alto ministerio, México, Imp. María de Benavides, 1696.

LezAmis, José, Breve relación de la vida y muerte del Illmo. y Rmo Señor Doctor D. Francisco de Aguiar y Seijas, México, Imp. María de Benavides, 1699.

Lumbier, Raymundo, Noticia de las sesenta y cinco proposiciones nuevamente condenadas por N. SS. P. Inocencio XI, México, Imp. Juan de Ribera, 1684.

Lumbier, Raymundo, Destierro de ignorancias, fragmento aureo..., México, Imp. Guillena Carrascoso, 1694.

Martínez López-Cano, María del Pilar, Reformas y resistencias en la Iglesia novohispana, México, Universidad Nacional Autónoma de México, 2014.

Mayer Celis, Leticia, Rutas de incertidumbre: ideas alternativas sobre la génesis de la probabilidad, siglos XVI y XVII, México, Fondo de Cultura Económica, 2015.

Maza, Francisco de la, Sor Juana Inés de la Cruz ante la historia, México, Universidad Nacional Autónoma de México, 1980.

MerLo, Nicolás, Espejo de indulgencias [sin dato de impresor], 1691.

Michel, Marie-José, Jansénisme et Paris, 1640-1730, París, Klincksieck, 2000.

MiguéLez, Manuel, Jansenismo y regalismo en España, Madrid, Editorial Agustiniana, 2010 [1895].

Millar Carvacho, René, “El obispo Alday y el probabilismo”, en Historia, 22 (1987), pp. 189-212.

NúÑEz De Miranda, Antonio, Explicacion literal y sumaria, al decreto de los Emin. Cardenales intérpretes del S. C. Tridentino contra algunos abusos que se ivan introduciendo en el uso de la comunión, León, Imp. Anisson, Posuel, y Rigaud, 1687. 
NúÑEz de Miranda, Antonio, Comulgador, y explicación mystica de la regla 18 de la Congregación de la Purísima, que es de la Conffesión y Comunión, México, Imp. Viuda de Miguel de Ribera, 1714 [1690].

Paz, Octavio, Sor Juana Inés de la Cruz o Las trampas de la fe, México, Fondo de Cultura Económica, 1982.

Préclin, Edmond, Histoire de l'Église depuis les origines jusqu'à nos jours, París, Bloud et Gay, 1956.

Quantin, Jean-Louis, Le rigorisme chrétien, París, Les Éditions du Cerf, 2001.

QuANTin, Jean-Louis, "Le rigorisme : sur le basculement de la théologie morale catholique au XvII e siècle", en Revue d'Histoire de l'Eglise de France, 89 (2003), pp. 23-43.

QUINTERo Í̃̃IGUEZ, Alejandro, "La infancia de un obispo del siglo XviI", tesis de maestría en historia, México, Universidad Iberoamericana, 2007.

Robles, Antonio, Diario de sucesos notables, México, Porrúa, 1972.

Rodríguez, Matías, Explicación de las sesenta y cinco proposiciones, Puebla, Imp. Fernández de León, 1684.

Rubial García, Antonio, "Votos pactados. Las prácticas políticas entre los mendicantes novohispanos", en Estudios de Historia Novohispana, 26 (ene.jun. 2002), pp. 51-83.

SÁNCHEz, Francisco, Examen de las indulgencias que legitimamente gozan las Religiones, y Cofradias, según las más modernas decisiones y decretos de los Romanos Pontifices, Madrid, Imp. Garcia Infancon, 1680.

Sánchez, Francisco, Rosario de la Virgen Maria Nuestra Señora, México, Imp. Maria de Benavides, 1684.

Sánchez, Francisco, Thesoro regvlar en compendioso sumario de indulgencias ciertas, que gozan los religiosos, religiosas, terceros, y terceras de las Ordenes Sagradas, Puebla, Diego Fernández de León, 1691.

Schuessler, Rudolf, The Debate on Probable Opinions in the Scholastic Tradition, Leiden, Brill's Studies, 2019. 
Tomsich, María Giovanna, El jansenismo en España: estudio sobre ideas religiosas en la segunda mitad del siglo XVIII, Madrid, Siglo Veintiuno Editores, 1972.

VÁzquEZ, Josefina Zoraida, Interpretaciones del siglo XVIII mexicano: el impacto de las reformas borbónicas, México, Nueva Imagen, 1992.

VeLASCo, Tomás, Breviloquio moral practico, en que se contienen las sesenta y cinco proposiciones probibidas por N. SS. P. Innocencio XI, declaradas por via de impugnación, México, Imp. Viuda Bernardo Calderón, 1681.

VÉNARD, Marc (coord.), Histoire du Christianisme: le temps des confessions, París, Déclée, 1992. 